http://jmscr.igmpublication.org/home/ ISSN (e)-2347-176x ISSN (p) 2455-0450

crossref DOI: https://dx.doi.org/10.18535/jmscr/v9i1.16

\title{
To Study S.CRP \& S.LDH Levels in Snake Bite Patients as a Markers of Hemotoxicity
}

Authors

Dr Metta Ranjini , Dr Padam Vijay Kumar², Dr Toleti Sai Phanindra ${ }^{3}$, Dr M. Madhusudhana Babu ${ }^{4}$, Dr Kanugula Sudheer ${ }^{5}$,

Dr B.Ashok Babu' ${ }^{6}$, Dr M.Yugandhar ${ }^{7}$

${ }^{1,2,3}$ Postgraduate,Department of General Medicine, Great Eastern Medical School \& Hospital, Ragolu, Srikakulam

${ }^{4}$ Professor, Department of General Medicine, Great Eastern Medical School \& Hospital, Ragolu, Srikakulam ${ }^{5}$ Professor \& HOD, Department of General Medicine, Great Eastern Medical School \& Hospital, Ragolu, Srikakulam.

${ }^{6,7}$ Senior Resident, Department of General Medicine, Great Eastern Medical School \& Hospital, Ragolu, Srikakulam

\section{Introduction}

Snake bite is considered as one of the medical emergency, either hemotoxic, neurotoxic, cytotoxic or a combination of these. The consequence of envenomation can range from minimal local tissue injury to multi-organ dysfunction. It is suspected that snake venom functions as an acute-phase reactant and interacts with target cells such as macrophages that release inflammatory mediators such as IL(Interleukin)-6 and 8. IL6 is believed to act on the liver, increasing acute phase reactants' production like c-reactive protein, ESR, serum amyloid, haptoglobin, etc ${ }^{1}$. Hemolysis, a typical manifestation of snake bite is thought to generate phospholipase, an essential component of snake venom. Serum lactate dehydrogenase (LDH) levels found to be associate well with snake venom hemotoxicity and snake bite envenomation severity $^{2}$. The ability to detect grade of envenomation at presentation is that of challenge and novel markers for the same would be a good guide for treatment as well at prognosis. Snakes are categorized into four families; these are Elapidae, Hydrophidae, Atractaspididae and Viperidae. In Indian subcontinent major families found to be Elapidae, which includes Common cobra, king cobra and krait, Viperidae that includes Russells viper, Pit viper and Saw-scaled viper and Hydrophidae. ${ }^{3}$

Of the 70 poisonous species in India majority of bites and consequent mortality is attributable to 5 species which are King Cobra (Ophiophagus Hannah), Common Cobra (NajaNaja), Russells viper (Daberia Ruselli), Saw-Scaled viper (Echis Carinatae) and Krait (Bungarus Caeruleus). ${ }^{3}$

\section{Grading of severity of envenomation}

Severity of envenomation is graded by the following scale. ${ }^{4}$

\begin{tabular}{|l|l|}
\hline No envenomation: \\
\hline Local manifestations & Mild pain \\
\hline Systemic manifestations & None \\
\hline Laboratory findings & None \\
\hline
\end{tabular}




\begin{tabular}{|l|l|}
\hline Mild envenomation & Swelling, erythema or echymosis confined to the site ob bite \\
\hline Local manifestation & None \\
\hline Systemic manifestations & None \\
\hline Laboratory findings & $\begin{array}{l}\text { Progression of swelling, erythema or ecchymosis beyond the site of } \\
\text { bite }\end{array}$ \\
\hline Moderate envenomation & $\begin{array}{l}\text { Non life threatening signs and symptoms. Perioral and peripheral } \\
\text { paresthesia, nausea, vomiting, diarrhea, ptosis, diplopia. }\end{array}$ \\
\hline Local manifestation & $\begin{array}{l}\text { Mildly abnormal coagulation profile with no features of systemic } \\
\text { bleeding. Mildly abnormal other laboratory tests. }\end{array}$ \\
\hline Systemic manifestations & \multicolumn{2}{|l|}{} \\
\hline Laboratory findings & Rapid swelling, erythema echymosis involving the entire part or body \\
\hline Severe envenomation & $\begin{array}{l}\text { Tachycardia,hypotension,tachypnoea,respiratory } \\
\text { paralysis,fasciculation, altered mental status,seizures }\end{array}$ \\
\hline Local manifestation & $\begin{array}{l}\text { Systemic bleeding or markedly altered coagulation profile, } \\
\text { unmeasurable INR, APTT and platelet count <20,000 }\end{array}$ \\
\hline Systemic manifestation
\end{tabular}

\section{Aims and Objectives}

1. To study the role of acute inflammatory marker serum CRP and serum LDH in cases of snake bite envenomation.

2. To study the prediction of early prognosis with the help of the above markers in snake bite patients

\section{Materials \& Methods \\ Source of Data}

The data for the study is collected from patients attended to Great Eastern Medical School \& Hospital, Ragolu, Srikakulam with a history of snakebite.

Study Period: October 2018 to march 2020.

Study Design: Cross sectional observational study.

Sample Size: 50 patients were selected for the study using purposive sampling technique based on inclusion and exclusion criteria after obtaining informed consent .On admission vital signs and site of bite were recorded.

Patients with history suggestive of snakebite, the following lab tests were included. Complete blood picture, ESR (erythrocyte sedimentation rate), PCV (packed cell volume), Urine routine and micro analysis, Serum CRP and LDH,, PT-INR (prothrombin time with international normalized ratio), APTT (activated partial thromboplastin time) all of which were done at admission and following 24 hours thereafter.

Clotting time, bleeding time and A 20 minute whole blood clotting test were repeated every $6^{\text {th }}$ hourly for the 1st 24 hours of hospital admission. Dry bites were defined as patients with a history of snakebite but withoutor signs or symptoms of local or systemic envenomation or lab abnormalities even after 24 hours of observation in the hospital. Patients were thereafter divided into no, mild, moderate and severe envenomation group based on a predetermined scale.

The above values were noted and a relation was drawn with the values of serum LDH and CRP levels.

\section{Inclusion Criteria}

Patients with alleged history of snakebite or unknown bites but with symptoms and signs compatible with snake bite envenomation

\section{Exclusion Criteria}

Any bite not caused by a snake.

Patients who received ASV prior to hospitalization.

Patients with history of known vasculitis, bleeding disorders, liver diseases, acute myocardial ischemia.

\section{Data Analysis}

Data entered in Excel sheet and analysed using SPSS 20 software. Collected data was analyzed by frequency, percentage, mean, standard deviation and $\mathrm{P}$ value calculated by Student $\mathrm{t}$ test and chi square test . MS word, Tables \& graphs were used to show the data. $\mathrm{P}$ value $<0.05$ is considered as statistically significant. 


\section{JMSCR Vol||09||Issue||01||Page 83-87||January}

\section{Results \& Discussion}

- The mean age of our study is $39.8 \pm 9.76$.

- Manifestations of envenomation are present in 46 patients. Of which 30 patients $(65.21 \%)$ had hemotoxic manifestations. 14 patients $(30.43 \%)$ had local envenomation. 2 patients $(4.34 \%)$ had neurotoxic manifestations. In a study done in Bangalore by Harshavardhana HS et al. ${ }^{7}, 60 \%$ were showed prolongation in the WBCT.

Table 1: Grade of Envenomation and its relation with S. CRP and LDH values

\begin{tabular}{|l|c|c|c|c|c|c|}
\hline Grade of Envenomation & $\begin{array}{c}\text { No. of } \\
\text { patients }\end{array}$ & Percentage & $\begin{array}{c}\text { CRP } \\
\text { Elevated }\end{array}$ & Percentage & $\begin{array}{c}\text { LDH } \\
\text { Elevated }\end{array}$ & $\begin{array}{c}\text { Percentage } \\
\text { No }\end{array}$ \\
Mild & 14 & $12 \%$ & 1 & $16.66 \%$ & 0 & 3 \\
Moderate & 20 & $28 \%$ & 5 & $35.71 \%$ & $21.42 \%$ \\
Severe & 10 & $20 \%$ & 16 & $80 \%$ & $70 \%$ \\
Total & $\mathbf{5 0}$ & & 10 & $100 \%$ & 10 \\
\hline
\end{tabular}

Figure 1: Grade of Envenomation and its relation with S. CRP and LDH values

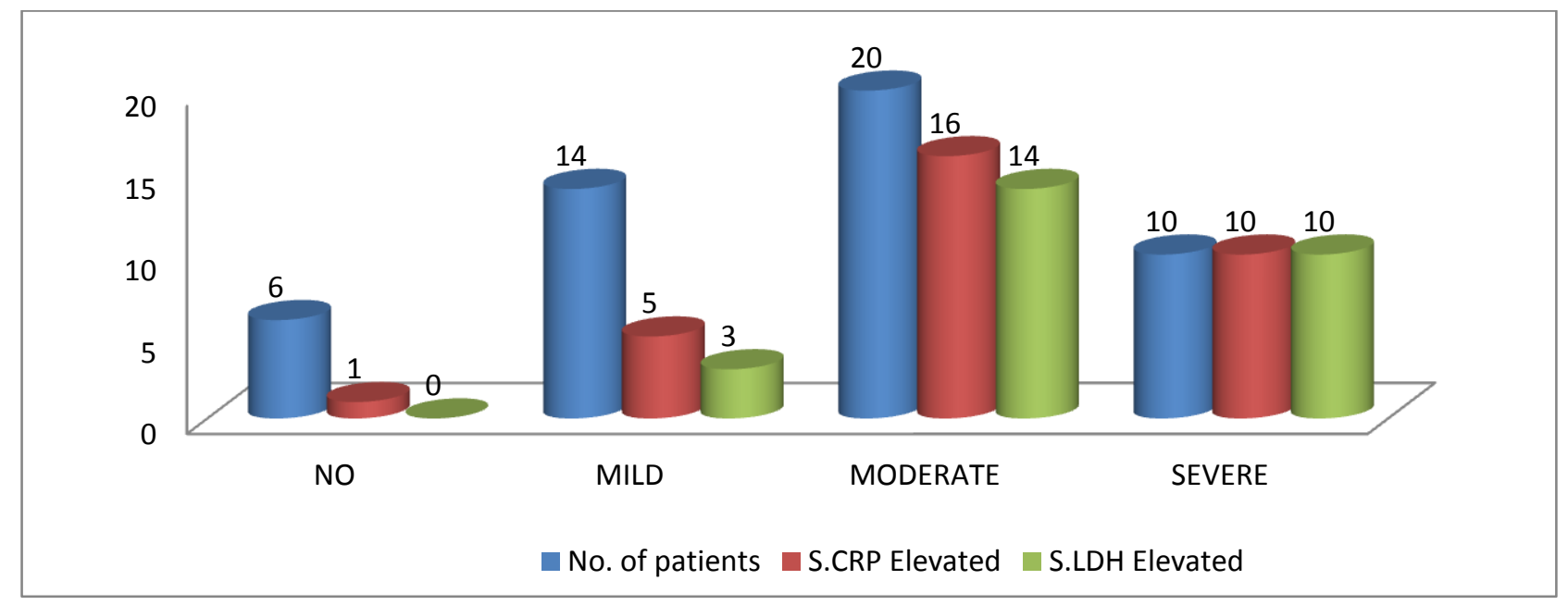

Table 2: Polyvalent ASV used and its comparison with S. CRP and LDH

\begin{tabular}{|l|c|c|c|c|c|c|}
\hline $\begin{array}{l}\text { Number of vials of } \\
\text { ASV }\end{array}$ & No. of patients & Percentage\% & $\begin{array}{c}\text { CRP } \\
\text { Elevated }\end{array}$ & Percentage\% & $\begin{array}{c}\text { LDH } \\
\text { Elevated }\end{array}$ & Percentage\% \\
\hline NIL & 08 & 16 & 03 & 37.5 & 0 & 0 \\
<10 & 13 & 26 & 07 & 53.84 & 03 & 23.07 \\
$10-20$ & 10 & 20 & 06 & 60 & 05 & 50 \\
>30 & 19 & 38 & 15 & 78.94 & 16 & 84.21 \\
TOTAL & 50 & & & & \\
\hline
\end{tabular}

In our study $19(38 \%)$ of the patients received more than 30 vials of polyvalent ASV. Of these S.CRP \& LDH levels are elevated in $15(78.94 \%)$ \& $16(84.21 \%)$ respectively whereas $10(20 \%)$ received 10-20 vials. Of these S.CRP \& LDH levels elevated in $6(60 \%) \& 5(50 \%)$ respectively and $13(26 \%)$ received less than 10 vials. Of these S.CRP \& LDH levels are elevated in 7(53.84\%) \& $3(23.07 \%)$ respectively

Table 3: Grades of envenomation and its comparison to S. CRP and LDH in our study group

\begin{tabular}{|c|c|c|c|c|c|c|}
\hline ENVENOMA-TION & $\begin{array}{c}\text { S.CRP at } \\
\text { PRESENTAT-ION }\end{array}$ & $\begin{array}{l}\text { S. CRP AT } \\
24 \text { HOURS }\end{array}$ & $\begin{array}{c}\text { P value of S.CRP } \\
\text { between at } \\
\text { presentation \& at } \\
24 \mathrm{hrs}\end{array}$ & $\begin{array}{l}\text { S. LDH AT } \\
\text { PRESENTAT- } \\
\text { ION }\end{array}$ & $\begin{array}{l}\text { S. LDH AT } \\
24 \text { HOURS }\end{array}$ & $\begin{array}{c}\text { P value of S.LDH } \\
\text { between at } \\
\text { presentation \& at } \\
24 \mathrm{hrs}\end{array}$ \\
\hline $\mathrm{NO}$ & $\begin{array}{c}3.10 \pm \\
2.68\end{array}$ & $\begin{array}{l}3.58 \pm \\
2.84\end{array}$ & 0.38 & $145.08 \pm 7.98$ & $\begin{array}{c}175.48 \pm \\
21.59\end{array}$ & 0.0001 \\
\hline MILD & $\begin{array}{c}9.86 \pm \\
2.78\end{array}$ & $15.36 \pm 5.88$ & 0.0001 & $208.06 \pm 8.07$ & $268 \pm 42.98$ & 0.0001 \\
\hline MODERATE & $22.41 \pm 15.56$ & $32.37 \pm 21.30$ & 0.0089 & $292.18 \pm 41.02$ & $\begin{array}{l}324.30 \pm \\
53.78\end{array}$ & 0.0002 \\
\hline SEVERE & $23.01 \pm 14.58$ & $33.03 \pm 22.48$ & 0.0095 & $335.75 \pm 82.68$ & $\begin{array}{l}370.07 \pm \\
97.19 \\
\end{array}$ & 0.0559 \\
\hline $\begin{array}{l}\mathrm{p} \text { value between mild and } \\
\text { severe envenomation }\end{array}$ & 0.0001 & 0.0001 & & 0.0001 & 0.0001 & \\
\hline
\end{tabular}


In our study S.CRP at presentation averages $9.86 \pm 2.78$ and at $24 \mathrm{hrs}$ it is $15.36 \pm 5.88$ in mild envenomation group whereas in severe group it is around $23.01 \pm 14.55$ at presentation and raised to $33.03 \pm 22.48$ with $\mathrm{p}$ values $0.0001 \& 0.0095$ in these groups. S.LDH at presentation averages $208.06 \pm 8.07$ and at $24 \mathrm{hrs}$ it is $268 \pm 42.98$ in mild envenomation group whereas in severe group it is around $335.75 \pm 82.68$ at presentation and raised to $370.07 \pm 97.19$ with $\mathrm{p}$ values $0.0001 \& 0.0559$ in these groups. There will be significant difference for S.CRP \& S.LDH at presentation and $24 \mathrm{hrs}$ after presentation between mild \& severe envenomation with $\mathrm{p}$ value 0.0001 in all grades of envenomation. There is statistically significant difference in the S CRP values both at admission and 24 hours later between the mild and severely envenomed group of patients ( $p$ value 0.0001 ) in our study. In a study by Xie $\mathrm{Y}$, et al, ${ }^{2}$ in china on victims of pit viper envenomation, patients were divided into mild, moderate and severely envenomed group. A significant difference was found in S.CRP levels between all the 3 groups ( $p$ $<0.01$ ).

The difference between the 2 groups among the grades of envenomation could be attributed to higher incidence of pit viper bites, differences in study population as well as systemic envenomation in their study group.

It was also noted that in our study that 4 patients with no features envenomation.

A study done by Bhagwat $\mathrm{K}$, et $\mathrm{al}^{6}{ }^{6}$ is similar to our study in Maharashtra on 50 patients of snakebite showed elevated S. LDH recordings at the time of admission and 24 hours later in snake bite victims as compared to the control group ( $p$ value $<0.05$ ) but our study did not have a control group. However there was found to be no similarity in the values of S.LDH between our study and that of Bhagwat $\mathrm{K}$, et $\mathrm{al}^{6}{ }^{6}$ ( $\mathrm{p}$ value $0.325)$. A study done by Kandaswamy $S$, et al. ${ }^{5}$ in Tamil Nadu involving 30 snakebite victims showed a statistically significant difference ( $p$ value 0.01) between S.LDH values recorded in haemotoxic snakebite victims and control group at admission. S. LDH values done at admission in patients with envenomation were found to be similar between our study and Kandaswamy S, et $\mathrm{al}^{5}$ ( $\mathrm{p}$ value 0.03 ).). This could be because of the similar profile of patients as well grade of envenomation in our group and that of Kandaswamy S, et $\mathrm{al}^{5}$.

\section{Summary}

The study was done to study the relationship between hemotoxicity and Serum CRP and LDH levels in snake bite victims.

1. Majority $(40 \%)$ of our patients presented with features compatible with moderate envenomation

2. Hemotoxic envenomation was the most common manifestation of envenomation in our study group (65.21\%)

3. A majority of our patients received 30 or more vials of Polyvalent ASV (38\%)

4. S.CRP showed a significant elevation in their levels at admission and 24 hours later with $\mathrm{p}$ value of $0.0001,0.0089,0.0095$ in mild, moderate \& severe grades of envenomation respectively.

5. S.LDH showed a significant elevation in their levels at admission and 24 hours later with $\mathrm{p}$ value of $0.0001,0.0002,0.0559$ in mild, moderate \& severe grades of envenomation respectively.

6. The values of S.CRP \& S.LDH were found to be raised in the severely envenomed group as compared to those with mild envenomation ( $p$ value 0.0001 ).

\section{Conclusion}

1. Most of the patients received more than 30 vials of Polyvalent ASV signifying higher incidence of systemic envenomation in our patients.

2. S.CRP \& S. LDH levels showed significant difference at the time of presentation and $24 \mathrm{hrs}$ after the admission in all grades of envenomation.

3. S. CRP \& S.LDH was found to be elevated significantly in the severe envonmation group as compared to those with mild 
envenomation.

4. Hence S.CRP \& LDH levels can serve as markers for hemotoxicity in snake bite victims and may help in predicting prognosis.

5. However, this needs to be studied in a larger population.

\section{References}

1. Kasturiratne A, Wickremasinghe AR, De Silva N, Gunawardena NK, Pathmeswaran A, Premaratna R, et al. The Global Burden of Snakebite:A Literature Analysis and Modelling Based on Regional Estimates of Envenoming and Deaths. PLoS.Med. 2008;5(11):e218.

2. Xie Y, Fu Q. The Relation of C-Reactive Protein of Sera With State of Toxicosis in Patients Bitten by AgkistrodonHalys. J of NanhuaUniv 2008;3:346-9.

3. Daniel JC. The book of Indian reptiles and amphibians. Mumbai oxford university press 2002; 1:74-5.

4. Gold BS, Dart RC, Barish RA. Bites of venomous snakes. N Engl J Med. 2002; 347:347-56.

5. Bhagwat K, Amar L.Blood hemoglobin, lactate dehydrogenase and total creatine kinase combinely as markers of hemolysis and rhabdomyolysis associated with snake bite. Int.J.Toxicol. Pharmacol.Res. 2013; 5:5-8.

6. Kandasamy $\mathrm{S}$, Gopalakrishnan $\mathrm{S}$, Venkatesan M, Ramakrishnan M. The clinical and biochemical profile of snakebite patients-A hospital based comparative study of envenomed and nonenvenomed victims. Int. J. Biochem. Biotechnol. 2014; 3(2):511-15.

7. Harshavardhana HS, Pasha I, Prabhu NCS, Amira, Ravi P. Snake Bite Induced Coagulopathy: A Study of Clinical Profile and Predictors of Poor Outcome. Int J Sci

Stud. 2014; 2:2-5. 